\title{
Shear stresses and velocity analysis of piercing process in Diescher's mill using Finite Element Method
}

\author{
Lu Lu, a and JIA Zhi Chun ${ }^{1, b}$ \\ ${ }^{1}$ College of Information Science and Technology, Bohai University, Jinzhou 121000, Liaoning, \\ China \\ alulu_me@163.com, ${ }^{b} 76763867 @ q q . c o m$
}

Keywords: FEM analysis, Tube piercing process, Shear stresses, velocity

Abstract. The finite element method (FEM) was used for simulation of piercing process of the tube in Diescher's mill. After a short description of the problem, the numerical model of the process was described. The simulated results visualize dynamic evolution of shear stresses and velocity in the piercing process. It shows that the distributions of shear stresses on the internal and external surface of the work-piece are mainly on the contact areas between the rolls and metal. The movement of mass points is not along circle direction but transverse. The reasons are analyzed. In conclusion, the position of plug should be located in the loose area and the discs should been arranged in a suitable position according to the ovalization of the workpiece forming.

\section{Introduction}

Nowadays products for the automotive industry have to meet higher quality demands and are to be developed in shorter times. Although the piercing process in skew rolling mills has been used in industry for more than hundred years, this technology has not so far been researched in a satisfactory way. The barrel-type rotary piercing is used widely in the world. Among the barrel-type rotary piercing, the best productivity and high quality of thick-walled tubes are obtained when two rolls rolling mills are used with two guiding discs of Diescher type ${ }^{[1]}$.

The Diescher tube piercing is very complex process of the material flow. The process relies on the cyclic mechanical loading of the material caused by the conical shape of the rolls and their rotation.To prevent such empiric procedure and reduce cost, numerical simulation of forming processes is applied increasingly and is becoming a very important tool for the design and development of new products. Finite Element Method (FEM) is most widely used in numerical simulation methods. Not only can it be used to proof the feasibility of the production process, but also to predict the microstructure and beyond that the properties of the component ${ }^{[2]}$.

Fig. 1 shows the material is pulled-in along a helical trajectory and a depressive mode causes a hole to form and develop in the billet.

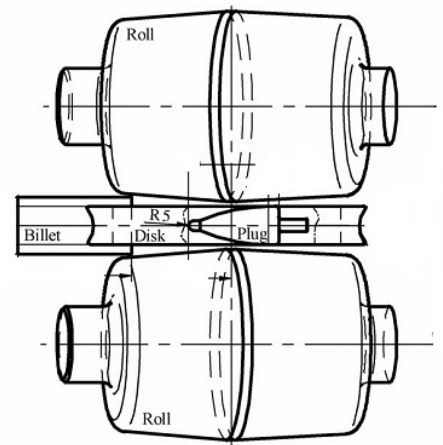

Fig. 1 Schematics of the process and the tools ${ }^{[3]}$ 


\section{Numerical model}

The software SuperForm $2005^{[4]}$ is used as the basis for modelling the process. Five tools are included in the model: two rolls, two shoes and a plug, as depicted in Fig. 2. The two rolls are rotating at 141 rotations/minute, and their axes form a $7^{\circ}$ angle. The diameter of the billet is $110 \mathrm{~mm}$ and it is assumed to be at $1255^{\circ} \mathrm{C}$ as it enters the roll bite. At the beginning of the deformation, the temperature of the rolls is taken as $100{ }^{\circ} \mathrm{C}$ and the plug is $300^{\circ} \mathrm{C}$. The constitutive law ${ }^{[5]}$ for the steel grade of interest writes:

$$
\sigma=m_{0} \exp \left(m_{1} T\right) \varepsilon^{m_{2}} \mathcal{E}^{\left(m_{3} T+m_{4}\right)} .
$$

The material parameters are obtained from experimental tests:

$$
\sigma=1.1244 \exp (6243.9238 / T) \cdot \varepsilon^{0.1571} \cdot \varepsilon^{(0.0003 T-0.1933)} .
$$

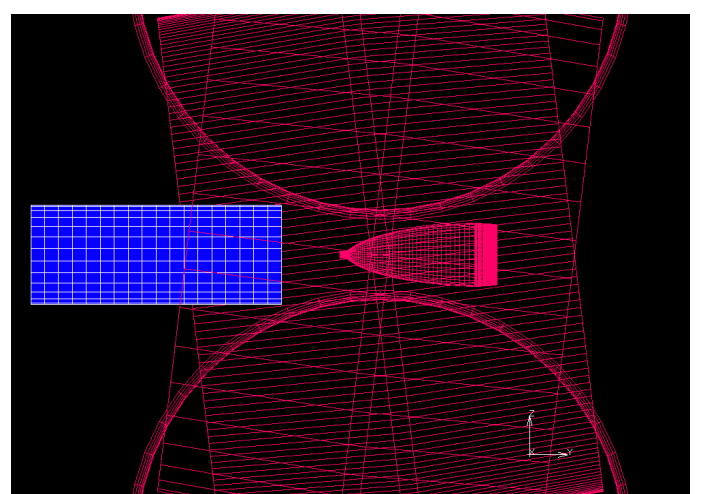

Fig. 2 Position of the tools in the numerical model

The contact with the billet and the rolls is assumed to be close to sticking friction. Sliding modes are applied to model the contacts between the billet and the guides.

\section{Distribution of Shear Stresses on Workpiece External Surface}

The FEM application allows for precise analysis of changes of shear stresses during piercing in the skew rolls piercing mill. Given the kinematics of the rolls, the billet tends to twist. This is observed in practice. It makes the simulation very difficult since the position is very sensitive to the friction model for instance. Fig. 3 presents the shear stresses distributions on workpiece external surface for the stable piercing phase. The analysis of data shows that the part of shear stresses distributions is mainly on the contact areas of workpiece external surface between the rolls and metal. The rolls speed is very fast, and the diameter ratio between the rolls and the workpiece is very large in the piercing process. The other part of shear stresses distributions are mainly on the contact areas of workpiece external surface between the discs and metal. This shows that there are many contacts between the discs and metal in the piercing process, so the shapes of discs are very important and influence hole cavity forming ellipticity. 


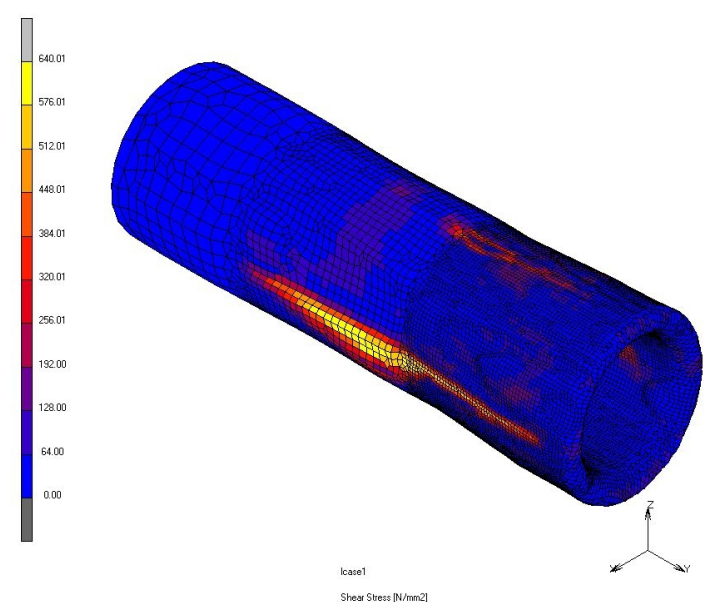

Fig.3 Shear stresses distributions on the workpiece external surface

\section{Distribution of Shear Stresses on the internal surface of workpiece}

The distributions of shear stresses on the workpiece internal surfaces are shown in Fig. 4. It shows that the maximum values of shear stresses are concentrated distribution in the parts where the plug just pierces into the workpiece. The position of plug should be located in the loose area in front of the hole cavity for avoiding infolding, increasing speeds of piercing, decreasing consumption of force energy and reducing the tools wear.

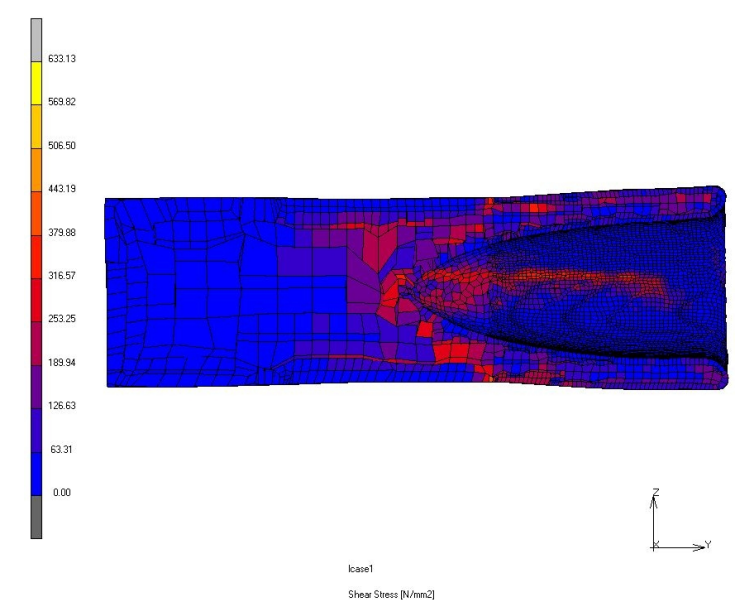

Fig.4 Shear stresses distributions on the workpiece internal surface

\section{Distribution of Velocity on Workpiece External and internal Surface}

Due to the application of FEM, it is possible to precisely analyze the changes of workpiece shape present during piercing process. Fig. 5 (a) and Fig. 5 (b) show the movement of workpiece is the motion at the same speed, so it is looked as the rigid rotation. The mass points of metal which are rolled and pieced by the rolls and plug move towards the metal inside, and the direction of surface velocity is to the surface direction of deformed tools when the workpiece is generally dragged into the deformed zone. The movement of mass points is not along circle direction but transverse, and velocity export direction after the workpiece is rolled along the transverse direction. It is the reason that the ovalization of the cross section appears in the piercing process. Therefore, the position and role of guide discs are very important, the discs should been arranged in a suitable position according to the 
ovalization of the workpiece forming. Because the movement of mass points is constrained by the discs, the movement of mass points is returned to the correct direction of the circular motion.

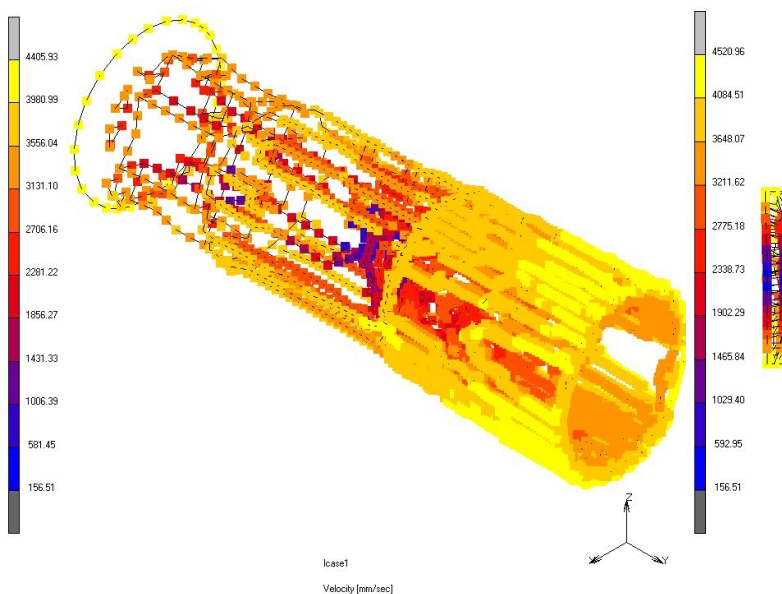

(a)

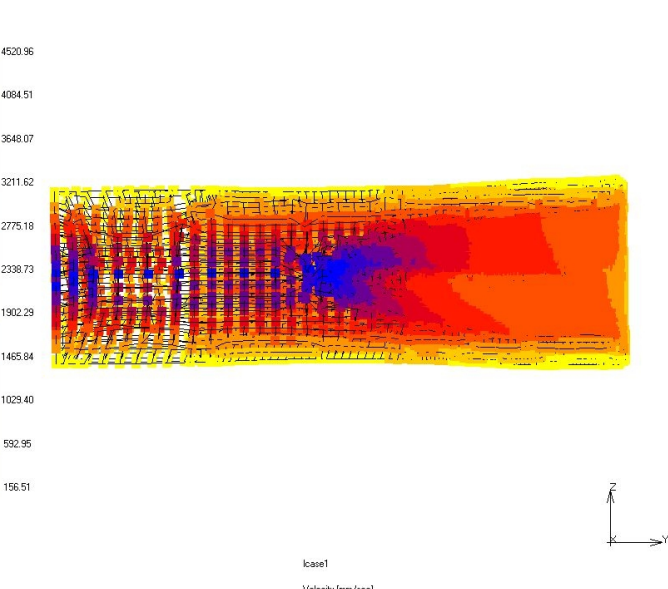

(b)

Fig.5 Velocity distributions on the workpiece external and internal surface

\section{Conclusions}

FEM simulation is performed to analyze the processing tube piercing of the new steel $33 \mathrm{Mn} 2 \mathrm{~V}$ for oil well tubes in this paper. Simulated results show the shear stresses distributions are mainly on the contact areas of workpiece external surface between the rolls and metal and the maximum values of shear stresses are concentrated distribution in the parts where the plug just pierces into the workpiece on the internal surface of the workpiece. Therefore the position of plug should be located in the loose area in front of the hole cavity for avoiding infolding, increasing speeds of piercing, decreasing consumption of force energy and reducing the tools wear.

Simulated results show the movement of mass points is not along circle direction but transverse, and velocity export direction after the workpiece is rolled along the transverse direction. Therefore, the position and role of guide discs are very important, the discs should been arranged in a suitable position according to the ovalization of the workpiece. Because the movement of mass points are constrained by the discs, the movement of mass points are returned to the correct direction of the circular motion.

\section{Acknowledgements}

This work was financially supported by the Liaoning Science Research Foundation (L2015007).

\section{References}

[1] Z. Pater, J. Kazanecki, J. Bartnicki: Journal of Materials Processing Technology. Vol.177 (2006), p. $167-170$

[2] J. Sinczak, J. Mahta, M. Glowacki, M. Pietrzyk: Journal of Materials Processing Technology. Vol.80-81(1998), p. 166-173

[3] Yang J., Li G., Wu W., Sawamiphakdi K., Jin D.: Materials Science \& Technology. Vol.2 (2004), p. $137-148$

[4] MSC. Software Corporation: MSC.SuperForm User's Guide Version 2005 (South Coast Metro, USA 2005) 
[5] Sellars C.M., Tegart: Aeta Metallurgica. Vol.14 (1966), p. 1136-1138 